\title{
Análise e Caracterização de Lesões de Pele para Auxílio ao Diagnóstico Médico
}

\author{
Alex F. de Araujo *, João Manuel R. S. Tavares, Roberta Barbosa Oliveira, \\ Ricardo Baccaro Rossetti, Norian Marranghello, Aledir Silveira Pereira
}

\begin{abstract}
Resumo: Neste capítulo, propõe-se uma metodologia híbrida para detectar e extrair os contornos de lesões de pele a partir de imagens, bem como a definição de características usualmente utilizadas no diagnóstico de lesões. O método de segmentação por divisão e união (Split and Merge) foi adotado para detectar a lesão e obter o seu contorno inicial. Em seguida, este contorno é refinado pelo modelo de contorno ativo tradicional. Características da lesão usadas na regra $\mathrm{ABCD}$, são definidas a partir do contorno refinado. Os resultados experimentais indicam que o método proposto é promissor para detectar as áreas com lesão e extrair seus contornos a partir de imagens, mantendo suas características.
\end{abstract}

Palavras-chave: Segmentação de Imagens Médicas, Lesões de Pele, Crescimento de Regiões, Contornos Ativos.

Abstract: A hybrid methodology for detecting and extracting skin lesion contours from images as well as the definition of common lesion diagnosis features are presented in this paper. The split and merge segmentation method has been applied for lesion detection and for the extraction of its initial contour. This contour is then adjusted using the traditional active contour model. Using the final contour characteristic features are defined according to the $A B C D$ rule. Experimental results show that the proposed method is promising in detecting ill areas as well as extracting their contours from images, while keeping lesions features.

Keywords: Medical Image Segmentation, Skin Lesions, Region Growing, Active Contour.

*Autor para contato: fa.alex@gmail.com 


\section{Introdução}

Metodologias computacionais para processamento e análise de imagens têm sido extensivamente pesquisadas, e várias soluções desenvolvidas para auxílio aos profissionais da área médica. Estas soluções visam ajudar no diagnóstico e no acompanhamento da evolução de doenças e dos planos de tratamento a partir de imagens, de forma rápida e precisa.

As lesões de pele são cada vez mais frequentes e podem indicar doenças graves, tal como o câncer de pele. Geralmente, o diagnóstico inicial destas lesões é feito a partir da análise de imagens obtidas através do exame de dermatoscopia ou de fotografias tiradas usando câmeras digitais convencionais. Para obter o diagnóstico inicial destas lesões, os dermatologistas analisam visualmente as imagens das regiões suspeitas. No entanto, alguns fatores, como o cansaço visual, a pequena dimensão de algumas lesões, especialmente quando ainda em estágio inicial de desenvolvimento, e as variações nas imagens causadas pela presença de ruídos e reflexos, tornam tal diagnóstico difícil, e por vezes impreciso.

Para a análise de imagens de lesões de pele, os dermatologistas utilizam frequentemente, as características da borda e da região interna das lesões para fazerem um diagnóstico inicial e visual das áreas de lesões. Os elementos que podem auxiliar no diagnóstico médico são a rugosidade e irregularidade das bordas das áreas lesionadas, a sua assimetria, diâmetro e variação de cor. Além disso, pode ser considerada também a evolução da lesão com o passar do tempo. A análise da evolução pode ser justificada devido a um aumento considerável do número de casos de câncer de pele causados pelo desenvolvimento de manchas ou lesões, que são afetadas por fatores externos, como a exposição excessiva ao sol (Guide, 2012). Assim, técnicas de processamento e análise computacional de imagem podem ser usadas para ajudar o dermatologista na realização de diagnósticos mais eficientes, extraindo os contornos e as características das lesões a partir das imagens em estudo.

Para que um método computacional de auxílio a diagnóstico de lesões de pele seja eficiente, o contorno extraído deve preservar as características de irregularidade da fronteira da lesão (Ma et al., 2010). Com o objetivo de detectar e extrair os contornos de lesões de pele a partir de imagens, mantendo sua integridade de detalhes, propõe-se desenvolver um método para processamento e análise das imagens de pele. Para atingir este objetivo aplicou-se o método de crescimento de regiões, seguido de uma etapa de pós-processamento, onde este contorno inicial é melhor ajustado à lesão pelo modelo de contorno ativo tradicional.

O crescimento de regiões foi implementado utilizando o algoritmo de "divisão e união"( split and merge), adotando o desvio padrão dos níveis das componentes do espaço de cor RGB (Red-Green-Blue) de cada quadrante como parâmetro de controle de crescimento. Após a divisão é realizada a 
união baseada na intensidade de cor das áreas da lesão em estudo, tornando possível a extração do seu contorno inicial. A topologia deste contorno inicial é similar à topologia da borda desejada. No entanto, o contorno inicial deve ser refinado para representar convenientemente a borda da lesão. Para tal refinamento, o método tradicional de contorno ativo é aplicado deformando este contorno inicial, de maneira a obter o novo contorno, sendo o mais próximo do real possível.

Neste capítulo, uma proposta de caracterização das lesões a partir das bordas obtidas das imagens é proposta. No método desenvolvido, para definir a rugosidade, a assinatura das bordas é extraída, analisando-se o tamanho e a quantidade de ispículos presentes na mesma. O diâmetro e a assimetria das áreas lesionadas são calculados a partir da distância entre os pixels do contorno, e a partir da localização do tecido lesionado obtem-se a variação de sua coloração.

Na sequência, tem-se na seção 2 o panorama geral da área em pesquisa. Na seção 3, descreve-se o método proposto. Uma discussão sobre os testes realizados e os resultados experimentais obtidos são incluídos na seção 4, seguido das conclusões e sugestões para trabalhos futuros.

\section{Enquadramento}

Para efetuar o processamento e análise de imagens de lesões é importante conhecer o problema a ser tratado, bem como as metodologias a serem utilizadas na resolução do mesmo.

\subsection{Diagnóstico de lesões de pele}

O alto índice de lesões de pele adquiridas de várias formas, e as consequências que elas podem trazer para o paciente, podendo vir a ser um câncer de pele, torna a sua detecção precoce muito importante para permitir a definição do plano de tratamento mais adequado. As lesões de pele provocadas por células cancerosas podem levar vários anos para se manifestar. No entanto, após se manifestarem, algumas lesões cancerosas podem crescer lentamente enquanto outras (os melanomas, por exemplo) podem crescer e se espalhar rapidamente pelo corpo (Guide, 2012). A demora na manifestação das lesões decorre do fato de que as cancerígenas geralmente se desenvolvem a partir de uma célula doente, a qual sofreu alguma mutação desordenada, provocando danos no seu DNA.

Para o diagonóstico das lesões de pele algumas características visuais como assimetria, irregularidade da borda, variação da cor interna e o diâmetro são observadas. Estas características são conhecidas como ABCD das lesões de pele (ou simplemente regra do ABCD). Na Tabela 1 apresenta-se o guia ABCD.

$\mathrm{O}$ fato dos melanomas crescerem e se modificarem rapidamente tem levado a uma reavaliação do guia $\mathrm{ABCD}$, onde pretende-se adicionar a 
característica "evolução", transformando o guia em ABCDE (Barcelos \& Pires, 2009). Uma pesquisa desenvolvida por Morris-Smith (Morris-Smith, 1996) revelou que os profissionais da área médica enfatizam muito estas características quando analisam as imagens de lesões, principalmente a irregularidade do contorno (Chen \& Liu, 2005). Este guia permite ao dermatologista fazer uma análise prévia da lesão, definindo os procedimentos a serem seguidos até que exames mais detalhados sejam feitos.

Tabela 1: Guia ABCD das lesões de pele (Adaptado de (Barcelos et al., 2003))

\begin{tabular}{|c|c|}
\hline Característica & Descrição \\
\hline Assimetria & $\begin{array}{l}\text { Simétrica: lesões que geralmente são não cancerosas } \\
\text { e/ou não malíginas, sendo mais arredondadas. } \\
\text { Assimétrica: lesões que possuem grande probabili- } \\
\text { dade de serem cancerosas e malígnas. }\end{array}$ \\
\hline Borda & $\begin{array}{l}\text { Lisa: lesões não malígnas possuem bordas lisas e su- } \\
\text { aves. } \\
\text { Rugosa ou cortada: frequentemente lesões malíg- } \\
\text { nas possuem bordas irregulares. }\end{array}$ \\
\hline Cor & $\begin{array}{l}\text { Regular: lesões com cor interna homogênea que, na } \\
\text { maioria das vezes, são não malígnas. } \\
\text { Irregular: geralmente os melanomas possuem co- } \\
\text { loração interna com grande variação das intensida- } \\
\text { des marrom e preta, podendo ter regiões isoladas em } \\
\text { branco. }\end{array}$ \\
\hline Diâmetro & $\begin{array}{l}<6 \mathbf{m m} \text { : lesões não malígnas geralmente possuem } \\
\text { diâmetro inferior a } 6 \mathrm{~mm} \text { e não variam de tamanho. } \\
\geq 6 \mathbf{m m} \text { : frequentemente os melanomas são maiores } \\
\text { do que } 6 \mathrm{~mm} \text { de diâmetro, crescem e mudam de forma } \\
\text { rapidamente. }\end{array}$ \\
\hline
\end{tabular}

As imagens de lesões de pele são obtidas, de forma não invasiva, a partir de máquinas fotográficas ou, mais detalhadamente por meio de um exame de dermatoscopia. Neste segundo caso, um instrumento óptico chamado dermatoscópio é usado para fazer a captura da imagem. Este equipamento possui lentes de aumento associadas a um sistema de iluminação, permitindo analisar as camadas mais profundas da pele. A principal vantagem de fazer a captura das imagens por dermatoscopia é o diagnóstico das lesões em seus estágios iniciais. No entanto, um fator negativo relacionado a este exame é que a maioria dos pequenos municípios não dispõem de tal tecnologia. Tal fato aumenta a importância de técnicas que permitam uma análise inicial das lesões a partir de imagens obtidas por máquinas fotográficas comuns. 
Através da visualização das imagens de pele, o dermatologista pode analisar a lesão, e suas características, a fim de ter uma idéia sobre a sua classificação. No entanto, esta análise não é tarefa fácil, devido a fatores como o cansaço visual do dermatologista, e a interferência causada por pêlos ou bolhas sobre a região lesionada. Uma forma de minimizar estes problemas é extrair o contorno destas regiões. Assim, a irregularidade das lesões fica mais evidente, evitando que a principal característica do guia ABCD seja distorcida em caso de cansaço visual.

\subsection{Segmentação de imagens médicas}

Geralmente, as técnicas de segmentação de imagens médicas são usadas para detectar estruturas, tais como órgãos, lesões, tumores e tecidos, representados em imagens, bem como extrair seus contornos de uma forma eficiente, robusta e automatizada. As pesquisas nesta área têm focado em métodos capazes de segmentar eficientemente as imagens afetadas por ruídos e outras interferências, evitando a perda das características principais da borda original, como a rugosidade, irregularidade e forma. Outra característica muito pesquisada é a automatização dos métodos na tentativa de evitar intervenções externas e subjetivas durante a etapa de análise computacional das imagens. Há métodos de segmentação baseados em diferentes conceitos e técnicas, como a limiarização de imagens, crescimento de regiões, algoritmos genéticos, redes neurais artificiais, modelos de contornos ativos e métodos híbridos (Ma et al., 2010).

\section{Limiarização}

As metodologias de segmentação baseadas em limiares tentam separar as regiões de interesse do fundo da imagem, usando valores como classificadores de uma característica particular (Gonzalez et al., 2003).

\section{Crescimento de região}

$\mathrm{Na}$ tentativa de unir o maior número possível de pixels em regiões homogêneas, têm sido propostos métodos baseados em crescimento de regiões (Lee et al., 2005; Celebi et al., 2008). Uma abordagem frequentemente usada é dividir a imagem de entrada em conjuntos de regiões disjuntas, tal como realizado pelo método de divisão e união. Esta abordagem consiste em dividir recursivamente a imagem original em quadrantes, até que um dado parâmetro de crescimento $P$ seja verdadeiro. Usualmente, este parâmetro é baseado nos níveis de intensidade de cada quadrante, como a média por exemplo. Então uma árvore é construída, onde cada nó não-folha possui 4 (quatro) nós filhos, os quais podem ser unidos de acordo com sua similaridade (Gonzalez et al., 2003). Diversas outras abordagens para crescimento de regiões têm sido propostas.

\section{Algoritmos genéticos}


Algoritmos genéticos (AG) têm sido usados na segmentação de imagens com características variadas (Hashemi et al., 2010; Mukhopadhyay \& Maulik, 2011). Os AG usam funções, conhecidas como operadores genéticos, para gerar novas populações a partir de uma população inicial, com o objetivo de produzir indivíduos mais aptos. Os operadores mais comuns são o de cruzamento e mutação. O primeiro recombina as características dos pais durante o processo de reprodução, resultando na herança de características pelas gerações seguintes. Este operador pode ser implementado de diferentes formas: cruzamento de ponto único, onde um ponto é selecionado para dividir os cromossomos dos indivíduos pais em duas partes, e então as informações genéticas (genes) dos pais são trocadas, passando uma das partes de um pai para o outro; e o cruzamento multi-ponto, onde os genes são trocados considerando mais do que um ponto de corte. O operador de mutação atua na manutenção da diversidade genética da população, evitando a estagnação na evolução dos indivíduos, que pode gerar resultados falsos-positivos.

\section{Redes neurais artificiais}

As redes neurais artificiais (RNA) são sistemas inteligentes, cuja meta é interpretar e resolver problemas computacionais baseando seu funcionamento no do cérebro humano (Babini \& Marranghello, 2007). Elas são capazes de adquirir conhecimento utilizando um grande conjunto de unidades de processamento, tratados por neurônios artificiais, interligados entre si, formando o que se conhece por sinapses artificiais. Essa estrutura confere às RNA uma capacidade de processamento paralelo e distribuído, garantindo-lhes características interessantes, do ponto de vista computacional, tais como: adaptabilidade, capacidade de aprendizado, habilidade de generalização, tolerância a falhas, possibilidade de armazenamento distribuído e facilidade de prototipagem (da Silva et al., 2010). Técnicas baseadas em RNA têm sido muito utilizadas para o reconhecimento de padrões (Bishop, 2004), em particular, dentro do escopo deste capítulo, para o processamento e análise de imagens médicas (Hudson \& Cohen, 2000).

\section{Modelos de contornos ativos}

Com o objetivo de desenvolver métodos de segmentação mais precisos e capazes de realizar a detecção aceitável de objetos e estruturas irregulares, várias técnicas de segmentação de imagens baseadas no modelo de contorno ativo proposto por Kass, Within e Terzopoulos (Kass et al., 1988) têm sido propostas. Usualmente, estes métodos iniciam com uma curva inicial, definida dentro do domínio da imagem, deformando esta curva em direção à borda desejada, pela ação de forças internas e externas aplicadas sobre a curva. Esta deformação é obtida pela minimização da energia da curva, sendo a energia mínima encontrada quando a curva 
está sobre a característica a ser segmentada. O uso dos métodos de segmentação baseados em contornos ativos tem sido muito explorado na análise de imagens médicas (Yoon et al., 2008; Lu \& Shen, 2006).

\section{Métodos híbridos}

Existe também uma tendência para unir diferentes técnicas (Jianli \& Baoqi, 2009; Dokur \& Ölmez, 2002; Araujo et al., 2011). Estas metodologias híbridas têm ganhado atenção especial devido à sua habilidade para produzir resultados mais precisos, além de processar imagens mais complexas. Por meio da combinação das características de duas ou mais técnicas, estas metodologias são usadas para superar algumas dificuldades da segmentação, tais como a heterogeneidade das regiões, as interferências de ruídos, as variações de posicionamento ou oclusões.

\section{Método proposto}

Nas imagens de lesões de pele existe a interferência causada por ruídos e outros artefatos, como pêlos, bolhas e interferências da iluminação. Além disso, as lesões de pele possuem formas, dimensões e tons variados. Assim, realizar a caracterização visual destas lesões é uma tarefa complexa, o que torna a extração eficiente das bordas de lesões crucial para facilitar o diagnóstico pelo dermatologista. Aqui é proposto um método híbrido para extrair contornos de lesões de pele a partir de imagens convencionais, usando as técnicas de crescimento de regiões e contornos ativos. Optouse por adotar as imagens obtidas por câmeras de imagem convencionais devido ao fato de uma boa parte dos exames iniciais ainda serem feitos a partir destas imagens, por falta de acesso ao dermatoscópio.

Na figura 1, apresenta-se o diagrama de fluxo do método proposto para realizar as tarefas de processamento, segmentação e caracterização das lesões a partir de imagens de pele. O método é baseado nos seguintes passos: pré-processamento, processamento, pós-processamento e caracterização.

As imagens de lesões de pele são geralmente coloridas e variadas, com diferentes formas e intensidades de ruído, como pêlos, bolhas e interferência da iluminação, dificultando sua caracterização visual. Desta forma, um filtro de redução de ruídos é aplicado para pré-processar a imagem original e tentar reduzir a interferência destes artefatos na etapa de segmentação. Nesta etapa, é desejável que as interferências sejam removidas e ao mesmo tempo as regiões dos contornos dos objetos mantidas. Diante disso, o método de suavização proposto por Barcelos e colaboradores em (Barcelos et al., 2003), é aplicado por apresentar bons resultados na remoção de ruídos e na manutenção das bordas em imagens de pele, como pode ser verificado em (Barcelos \& Pires, 2009).

A extração das bordas das lesões de forma eficiente é importante para facilitar a análise da rugosidade do contorno das regiões lesionadas pelo 
dermatologista. Várias técnicas de segmentação podem ser aplicadas para realizar esta tarefa. No entanto, para obter bordas mais precisas, as tarefas de extrair os contornos é dividida em duas etapas: detecção do contorno da lesão e refinamento desse contorno. Em cada etapa foi aplicado um método de segmentação, na tentativa de obter contornos que mantivessem a integridade de suas características.

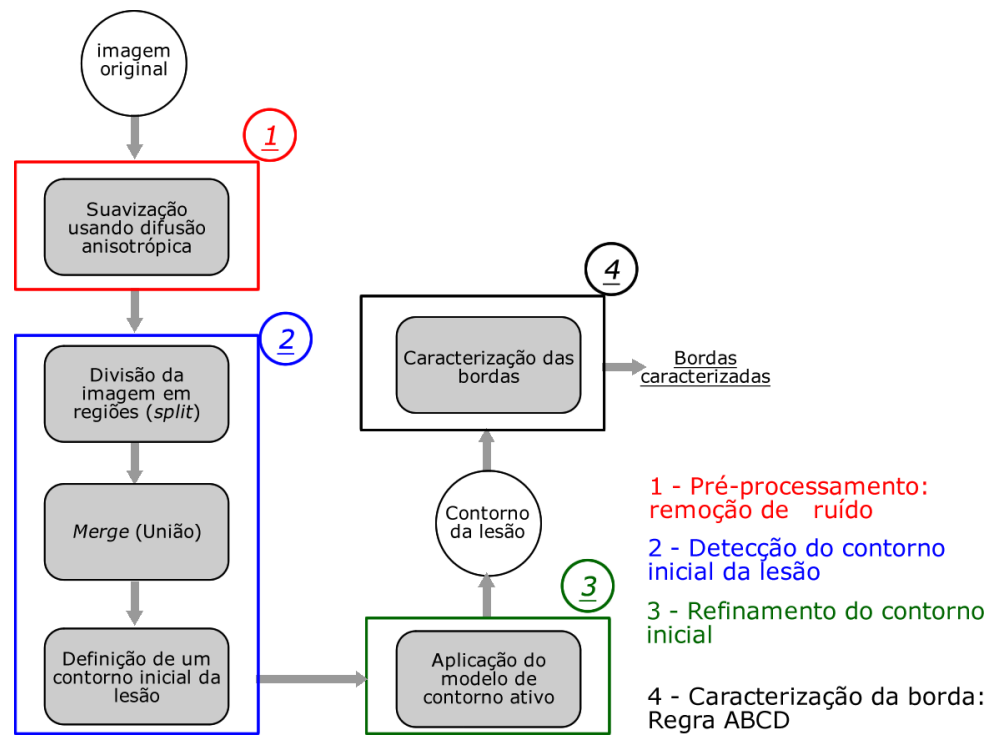

Figura 1: Diagrama de fluxo do método proposto.

Após a redução das interferências causadas pela presença de ruídos, o segundo passo do método é aplicado na imagem para detectar a área lesionada e extrair um contorno inicial para esta. Partindo do conhecimento a priori sobre as lesões de pele analisadas, nota-se que geralmente as áreas lesionadas apresentam intensidades de cores mais escuras do que as regiões não lesionadas. Assim, o método de segmentação baseado em divisão e união foi adotado para esta etapa, por permitir dividir a imagem em regiões distintas de acordo com a similaridade de seus pixels. Nesta segmentação inicial, cada componente do sistema de cores RGB é processada separadamente e unidas posteriormente. Na tentativa de aceitar apenas os quadrantes da imagem que possuam uma variação de intensidade reduzida, adotou-se o desvio padrão das intensidades dos pixels de cada quadrante como parâmetro de crescimento. Sendo a imagem suavizada dividida até que o desvio padrão do quadrante seja inferior a $20 \%$ do desvio padrão 
da imagem antes da divisão. Este valor foi definido experimentalmente a partir de testes realizados sobre o conjunto de imagens analisadas. Assim, a divisão acontece até que este parâmetro seja satisfeito ou, no pior caso, até que o quadrante tenha dimensões iguais a 2x2 pixels e assim não seja mais divisível.

O passo seguinte permite que as imagens suavizadas sejam representadas por um conjunto de regiões homogêneas, facilitando a detecção das regiões de pele que são potenciais áreas lesionadas. Para unir as várias regiões segmentadas e isolar o fundo da imagem, um algoritmo de união é aplicado considerando a distância entre as intensidades das regiões e agrupando as regiões com intensidades similares. O resultado é uma imagem binarizada, a qual torna possível a extração dos contornos aproximados para as lesões pela avaliação das intensidades dos seus pixels.

$\mathrm{Na}$ maioria das imagens testadas, os contornos aproximados obtidos pelo método de crescimento de regiões foram coincidentes com a topologia das bordas das lesões. No entanto, apesar destes contornos possuírem topologia semelhante à topologia das lesões, eles não envolveram toda área doente das mesmas, necessitando de um melhor ajuste para coincidir com o contorno desejado. Estes contornos iniciais são então melhor ajustados para a fronteira da lesão pelo uso de um método de contorno ativo. Para este refinamento foi adotado o modelo de contorno ativo tradicional (snakes) (Kass et al., 1988), que tem como uma de suas características, a manutenção da topologia da curva inicial. O peso das forças externas adotado experimentalmente foi 0.1 , e os parâmetros de elasticidade de rigidez foram considerados iguais e com valor 0.05 para todas as imagens. É importante ressaltar que os parâmetros adotados foram baixos para garantir a manutenção da topologia borda inicial da lesão e também para que a deformação da curva com o passar do tempo ocorresse lentamente, uma vez que a curva inicial pode-se encontrar próximo do limite desejado.

Com a última etapa do método proposto tenta-se extrair características das imagens que possam ser usadas para ajudar o especialista médico na definição das lesões a partir da regra ABCD, as quais são importantes por possibilitarem um diagnóstico inicial do tipo das lesões cancerosas.

A partir da borda da lesão detectada e extraída a caracterização pode ser feita calculando-se primeiramente o diâmetro do contorno $(D)$, seguidos do cálculo da assimetria $(A)$, irregularidade da borda $(B)$ e variação da cor interna $(C)$. De acordo com os especialistas médicos, o diâmetro da lesão é considerado como sendo o maior segmento de reta que corta a região lesionada, ligando dois pontos do seu contorno. Assim, adotou-se a maior distância euclidiana entre os pares de pontos do contorno para definir o diâmetro da lesão.

O cálculo do diâmetro foi o primeiro passo da caracterização devido à importância da maior diagonal da lesão para a definição de sua assimetria. 
Aqui é proposto classificar as lesões em três classes de acordo com a sua assimetria: simétrica, levemente assimétrica e acentuadamente assimétrica. Esta classificação é feita a partir da análise das semi-retas perpendiculares à diagonal maior. Primeiramente, são definidas todas as linhas que ligam os pontos do contorno, cruzando a diagonal maior, e que sejam perpendiculares a esta. Em seguida, divide-se cada linha no ponto de interseção com a diagonal maior, obtendo duas novas linhas, uma de cada lado da diagonal maior, como ilustrado na figura 2 pelas linhas $\left(L_{1}\right)$ na cor rosa, e $\left(L_{2}\right)$ em amarelo.

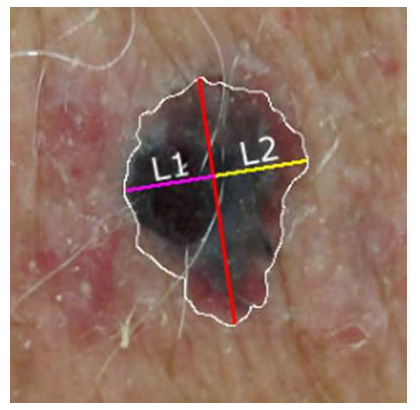

Figura 2: Exemplo de comparação de uma linha perpendicular à diagonal maior usada para definir a assimetria da lesão.

Após a divisão da linha perpendicular à diagonal maior, calcula-se a diferença de tamanho entre os seus segmentos $\left(L_{1}\right)$ e $\left(L_{2}\right)$, definindo a porcentagem desta diferença em relação ao maior dos segmentos. Assim, a diferença fica definida em função do maior lado da linha perpendicular. Este cálculo é feito para todas as perpendiculares. Para definir à qual classe de assimetria a lesão pertence, foram definidos dois limiares $T_{1}$ e $T_{2}$, usados para dividir o conjunto de perpendiculares à diagonal principal em três grupos: Grupo 1 contendo as perpendiculares cuja diferença for menor ou igual a $T_{1} ;$ Grupo $_{2}$ para as perpendiculares cuja diferença for maior do que $T_{1}$ e menor ou igual a $T_{2}$; e Grupo $_{3}$ com as perpendiculares cuja diferença for maior do que $T_{2}$.

Com o objetivo de definir estes limiares de forma que pudessem ser usados para todas as imagens do conjunto de testes, analisou-se a distribuição das porcentagens obtidas através das diferenças entre os segmentos $L_{1}$ e $L_{2}$ das retas perpendiculares à diagonal maior. O histograma obtido é formado por 100 colunas (referentes aos 100\%), onde em cada coluna armazena-se a quantidade de diferenças com cada porcentagem. A partir da análise dos histogramas de uma amostra de 9 imagens do conjunto de testes, percebeu-se que ocorreu uma maior concentração entre os valores 
0\% (zero) e $30 \%$ para as bordas simétricas, e acima de $45 \%$ para as acentuadamente assimétricas. É importante ressaltar que as lesões usadas para análise dos histogramas tiveram suas assimetrias previamente definidas por uma análise visual de um dermatologista, sendo 3 imagens pertencentes a cada um dos grupos de assimetria definidos no trabalho. Assim, adotouse $T_{1}=30$ e $T_{2}=45$. Com estes limiares as lesões foram classificadas dividindo-as em classes da seguinte forma: simétrica se o Grupo contiver $_{1}$ mais elementos do que os demais; levemente assimétrica se o Grupo $_{2}$ for maior que os restantes; e acentuadamente assimétrica se o Grupo $_{3}$ contiver mais elementos.

Para definir a irregularidade das bordas, propôs-se, uma abordagem baseada nos pontos de inflexão. Estes pontos são aqueles em que as curvas mudam de côncavas para convexas, ou vice-versa. Para encontrar estes pontos em que as bordas mudam de direção, desenvolveu-se duas técnicas. A primeira retira a assinatura da borda, e através desta procura os pontos em que ocorrem mudanças de direção, definindo seus pontos de inflexão (picos e vales). A segunda técnica percorre a assinatura da borda, calculando o produto vetorial entre dois vetores definidos por pontos pertencentes a esta.

Para a primeira técnica percorre-se todos os pontos $p_{i}$ da assinatura da borda, analisando os quatro vizinhos do lado esquerdo e os quatro do lado direito de $p_{i}$. Na imagem (a) da figura 3, tem-se o esquema de um ponto de inflexão na cor vermelha, e seus quatro vizinhos à esquerda (na cor azul) e à direita (na cor verde).

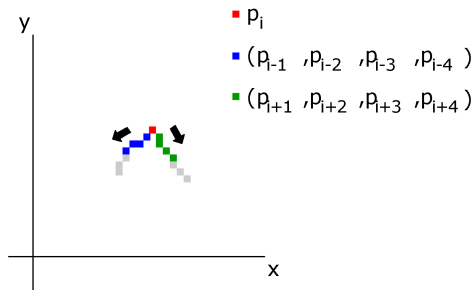

(a)

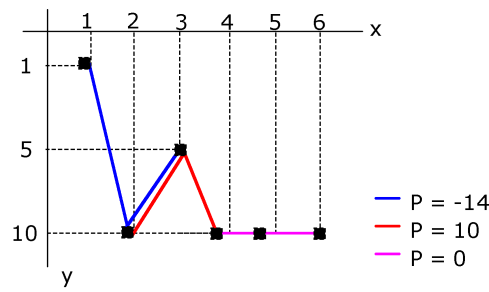

(b)

Figura 3: Exemplo de um ponto de inflexão e seus vizinhos direitos e esquerdos na imagem (a), e exemplo de produto vetorial na imagem (b).

Para determinar se o ponto $p_{i}$ é uma inflexão, definiram-se pesos para cada um dos oito vizinhos de $p_{i}$ (os quatro da direita e os quatro da esquerda) da seguinte forma: se o vizinho estiver abaixo de $p_{i}$ em relação à coordenada $y$, ele recebe peso 1 , senão, ele recebe peso -1 . Para os casos onde a soma dos pesos for superior ou igual a 2 , ou inferior ou igual a -2 , para ambos os lados, considera-se a existência de uma inflexão. Caso 
seja detectada uma mudança de direção e a soma dos pesos seja positiva, a inflexão é um pico, caso seja negativa é um vale. Assim, cada ponto de inflexão está associado a uma oscilação da borda.

Cada ispículo é formado por um pico cercado por um vale à direita e outro à esquerda. Como este método faz uma análise apenas dos vizinhos próximos de $p_{i}$, ele retorna as pequenas variações da borda, dificultando a detecção dos ispículos maiores. Na tentativa de obter um método para definição dos ispículos maiores, desenvolveu-se uma segunda técnica para calcular as inflexões, baseando-se no produto vetorial. Considerando três pontos, $p_{1}=\left(x_{1}, y_{1}\right), p_{2}=\left(x_{2}, y_{2}\right)$ e $p_{3}=\left(x_{3}, y_{3}\right)$ pertencentes à borda da lesão, pode-se definir o direcionamento da curva formada pelos pontos $\left(\widehat{p_{1} p_{2} p_{3}}\right)$, a partir do produto vetorial entre os vetores definidos pelos pontos $p_{1} \vec{p}_{2}$ e $p_{2} \vec{p}_{3}$. Usando a convenção de leitura da imagem, isto é, da esquerda para a direita e de cima para baixo, tem-se que se o produto vetorial $p$ for maior que 0 (zero), $p_{1}, p_{2}$ e $p_{3}$ constituem um pico, se for menor que 0 (zero) constituem um vale, e se for igual a 0 (zero) formam uma reta.

$$
p=\left(x_{2}-x_{1}\right) \cdot\left(y_{3}-y_{1}\right)-\left(y_{2}-y_{1}\right) \cdot\left(x_{3}-x_{1}\right)
$$

$\mathrm{Na}$ imagem (b) da figura 3, têm-se exemplos de três sequências de pontos e o seu produto vetorial. Pode-se observar que a curva azul forma um vale (produto vetorial negativo), enquanto a vermelha forma um pico (produto vetorial positivo) e a rosa forma um segmento de reta (produto vetorial igual a 0 (zero)). Vale ressaltar que apenas na imagem (b) desta figura foi exibido o sistema de coordenadas com a origem no canto superior esquerdo. A mudança para esta imagem foi feita apenas para facilitar o entendimento de como o produto vetorial foi usado para definir os picos e vales.

A técnica que utiliza o produto vetorial considera os vetores formados pelos pontos $\left(p_{1}-15 ; p_{i} ; p_{i}+15\right)$, sendo $1 \leq i \leq n$, e $n$ o número de pontos da borda. Esta variação de 15 pixels para a esquerda e para a direita foi adotada para descartar os ispículos muito pequenos, que já foram calculados pela técnica anterior. Assim, esta etapa do método calcula a quantidade de ispículos e vales grandes, e também a quantidade de ispículos e vales pequenos. As duas informações são importantes para definir, respectivamente, a irregularidade e a rugosidade dos contornos das lesões.

A variação da coloração interna das lesões foi calculada usando o canal $H$ (matiz) do sistema de cores $H S V$. Este canal foi escolhido por conter a variação de cor de uma imagem. Para definir a quantidade de cores do tecido doente, a matiz foi dividida linearmente em 10 intervalos, chamados de classes de cores. Todas as cores pertencentes a um mesmo intervalo foram consideradas semelhantes. Assim, para calcular a quantidade de cores da lesão, percorre-se a região limitada pelo contorno, contando quantos 
pixels existem em cada um dos intervalos de cor. Após fazer esta contagem, descartam-se as classes que contêm menos de 100 pixels. Isto é feito para evitar que pixels isolados, ou regiões muito pequenas (como pequenos artefatos) interfiram na contagem do número de cores da lesão.

\section{Resultados}

Os testes experimentais do método proposto foram feitos em um conjunto de imagens de pele com lesões, formado por 40 imagens coloridas, com resolução de 256x256 pixels, retiradas de (Dermatlas, 2012) e (Goshtasby, 2012). Foram utilizadas imagens contendo lesões de três classificações: lesões atípicas, lesões malignas e lesões não-malignas. As imagens desta fonte foram usadas porque, além das imagens, são disponibilizadas também informações sobre o diagnóstico final das regiões afetadas. O conjunto de imagens adotado foi formado por imagens variadas, possuindo imagens com bom contraste, baixo contraste, afetadas por diferentes quantidades de ruído e artefatos, como pêlos, bolhas e reflexos de luz. A validação dos resultados foi feita por um especialista em doenças dermatológicas.

A figura 4 contém algumas imagens processadas pelo método desenvolvido. Nesta figura tem-se as imagens originais e suas respectivas bordas, resultantes da aplicação da etapa de segmentação proposta. A lesão da imagem 1 é uma lesão atípica, da 2 e 3 são não-malignas e da 4 e 5 foram diagnosticadas como lesões malignas.

Nas imagens apresentadas, nota-se que as lesões foram detectadas e envolvidas pelo contorno final. Todos os contornos finais obtidos foram visualmente avaliados pelo especialista que confirmou que as lesões existentes nas imagens em estudo foram detectadas com sucesso. Após detectar as lesões e extrair suas bordas, aplicou-se a etapa de caracterização das lesões. Nesta etapa, o objetivo é extrair características que possam ser usadas para diagnosticar as áreas doentes de acordo com a regra ABCD. Na tabela 2, tem-se os dados retornados por esta etapa para as mesmas imagens da figura 4 .

$\mathrm{Na}$ segunda coluna da tabela 2, tem-se a classificação das lesões de acordo com a sua simetria. A quantidade de ispículos grandes e pequenos aparece na terceira coluna. Estes dados foram retornados para que o dermatologista tenha a ideia da irregularidade das bordas. Vale ressaltar que, para fazer a analise da irregularidade, deve-se considerar o tamanho da lesão, uma vez que a tendência é que o numero de ispículos seja menor quando a região doente for menor.

Pelos resultados percebeu-se também que nas lesões atípicas e malignas, a quantidade de cores internas foi maior do que nas lesões não-malignas. Ao passo que foram encontradas poucas cores nas lesões não malignas, na maior parte das malignas detectou-se mais de 5 cores, o que também atende a regra $\mathrm{ABCD}$. 


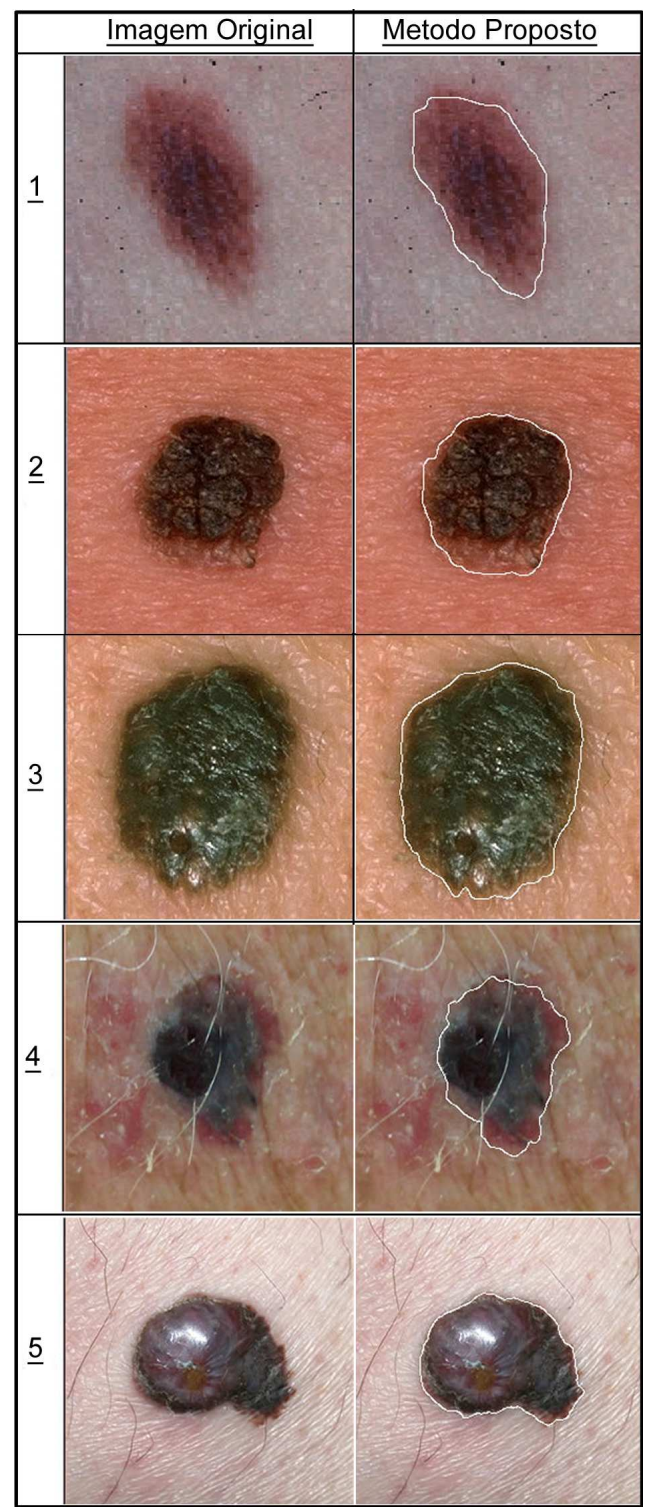

Figura 4: Resultados do método proposto aplicado a imagens com diferentes características. 
Tabela 2: Características extraídas das lesões

\begin{tabular}{|c|c|c|c|c|}
\hline Img & Assimetria & Irregularidade da borda & Cores & $\begin{array}{l}\text { Diâmetro } \\
\text { (Pixels) }\end{array}$ \\
\hline 1 & $\begin{array}{l}\text { Levemente Assi- } \\
\text { métrica }\end{array}$ & $\begin{array}{l}7 \text { ispículos e } 5 \text { vales grandes, e } \\
13 \text { ispículos pequenos }\end{array}$ & 9 & 167 \\
\hline 2 & $\begin{array}{l}\text { Levemente Assi- } \\
\text { métrica }\end{array}$ & $\begin{array}{l}8 \text { ispículos e } 1 \text { vale grandes, e } 18 \\
\text { ispículos pequenos }\end{array}$ & 1 & 150 \\
\hline 3 & $\begin{array}{l}\text { Levemente Assi- } \\
\text { métrica }\end{array}$ & $\begin{array}{l}11 \text { ispículos e } 4 \text { vales grandes, e } \\
25 \text { ispículos pequenos }\end{array}$ & 4 & 216 \\
\hline 4 & $\begin{array}{l}\text { Acentuadamente } \\
\text { Assimétrica }\end{array}$ & $\begin{array}{l}6 \text { ispículos e } 3 \text { vales grandes, e } \\
18 \text { ispículos pequenos }\end{array}$ & 10 & 162 \\
\hline 5 & $\begin{array}{l}\text { Acentuadamente } \\
\text { Assimétrica }\end{array}$ & $\begin{array}{l}6 \text { ispículos e } 3 \text { vales grandes, e } \\
21 \text { ispículos pequenos }\end{array}$ & 8 & 149 \\
\hline
\end{tabular}

A medida do diâmetro foi calculada em pixels, pois a maioria das imagens usadas nos testes não trazia informações que permitissem montar uma relação, e definir aproximadamente esta medida em milímetros. Para demonstrar a validade do cálculo do diâmetro usado, apresenta-se na figura 5 uma imagem com uma referência para cálculo da distância em milímetros. $\mathrm{Na}$ figura 5, em (a) tem-se uma imagem contendo uma lesão de pele com aproximadamente 5 milímetros de diâmetro, como pode-se observar pela régua usada como referência na parte superior da imagem (a). Na imagem (b) tem-se o valor em milímetros $(4.73 \mathrm{~mm})$, do diâmetro calculado pelo método de caracterização desenvolvido. Este cálculo foi feito a partir da relação entre o número de pixels da maior diagonal da lesão, e o número de pixels necessários para representar cada milímetro na imagem original. A borda da lesão e o seu diâmetro foram processados adequadamente por meio do método desenvolvido.

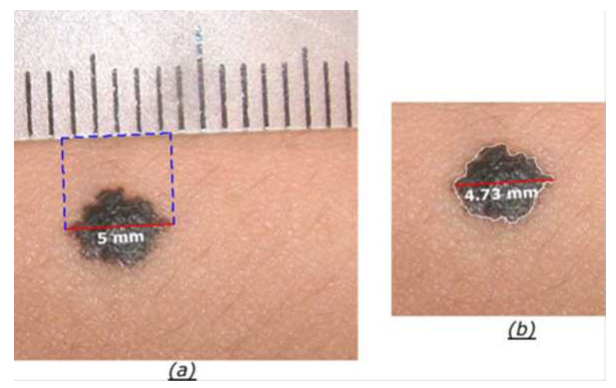

Figura 5: Cálculo do diâmetro da lesão. Em (a) o diâmetro da lesão definido pelo especialista, e em (b) o diâmetro calculado a partir da borda retornada pelo método proposto. 
Após obter estes resultados, foi avaliada a qualidade das bordas finais detectadas e extraídas. Os dados desta análise são apresentados na tabela 3 .

Tabela 3: Avaliação da qualidade das bordas finais, considerando o conjunto de imagens adotadas para teste

\begin{tabular}{l|l}
\hline Resultados aceitáveis & Resultados ruins \\
$92 \%$ & $8 \%$ \\
\hline
\end{tabular}

A partir dos dados apresentados nas tabelas 2 e 3 , verifica-se que o procedimento desenvolvido é promissor, e obteve um bom desempenho. Todos os contornos finais obtidos foram visualmente avaliados pelo especialista que confirmou que as lesões existentes nas imagens em estudo foram todas detectadas com sucesso, e em aproximadamente $92 \%$ dos casos, os contornos extraídos foram considerados aceitáveis pela avaliação médica, envolvendo todas as áreas lesionadas nas imagens.

\section{Conclusões}

Um método híbrido para segmentação de imagens coloridas de lesões de pele foi apresentado. O método desenvolvido une as características das técnicas de crescimento de regiões e de contornos ativos para detectar, extrair e refinar as bordas das lesões, preservando suas características principais.

A partir da análise visual dos resultados obtidos, realizada por um especialista médico, pode-se concluir que o método proposto é promissor, sendo capaz de detectar as prováveis regiões doentes em imagens de lesões de pele, obtidas a partir de fotografias convencionais.

No entanto, o método proposto ainda possui algumas limitações quando a imagem original possui transições muito suaves entre as regiões doente e saudável, quando existe a presença de reflexos sobre as transições, ou quando as lesões encontram-se no couro cabeludo e existe uma presença excessiva de pêlos na região lesionada. Para superar o problema das transições muito suaves, pretende-se realizar testes usando outros métodos de contorno ativo para pós-processar as imagens, na tentativa de realizar uma deformação mais adequada do contorno aproximado dado pelo método de crescimento de regiões. Além disso, na tentativa de solucionar as falhas para extrair o contorno das lesões no couro cabeludo e com reflexos, serão testados outros parâmetros para a metodologia de suavização adotada. Outra etapa a ser desenvolvida na sequência é uma comparação estatística do método proposto com os métodos existentes. 


\section{Agradecimentos}

O primeiro autor gostaria de agradecer à Fundação para a Ciência e a Tecnologia (FCT), em Portugal, pela sua bolsa de Doutoramento com referência SFRH/BD/61983/2009.

Os autores são gratos à Coordenação de Aperfeiçoamento de Pessoal de Nível Superior (CAPES), no Brasil, pelo suporte financeiro.

Este trabalho foi parcialmente desenvolvido no escopo dos projetos "Methodologies to Analyze Organs from Complex Medical Images - Applications to Female Pelvic Cavity", "Aberrant Crypt Foci and Human Colorectal Polyps: mathematical modelling and endoscopic image processing"e "Cardiovascular Imaging Modeling and Simulation - SIMCARD", com as referências PTDC/EEA-CRO/103320/2008, UTAustin/MAT/0009/2008 e UTAustin/CA/0047/2008, respectivamente, suportados pela FCT.

\section{Referências}

Araujo, A.F.; Tavares, J.M.R.S.; Oliveira, R.B.; Marranghello, N.; Pereira, A.S. \& Rossetti, R.B., Uma metodologia híbrida para segmentação de lesões de pele. In: Anais do VII Workshop de Visão Computacional. IEEE Computer Society, v. 1, p. 173-178. 2011.

Babini, M. \& Marranghello, N., Introdução às redes neurais artificiais. $1^{\text {st }}$ edição. São José do Rio Preto, SP: Laboratório Editorial do IBILCE, UNESP: Cultura Acadêmica, 2007.

Barcelos, C. \& Pires, V., An automatic based nonlinear diffusion equations scheme for skin lesion segmentation. Applied Mathematics and Computation, 215(1):251-261, 2009.

Barcelos, C.A.Z.; Boaventura, M. \& Silva, E.C., A well-balanced flow equation for noise removal and edge detection. IEEE Transactions on Image Processing, 12(1):751-763, 2003.

Bishop, C.M., Neural networks for pattern recongition. $1^{\text {st }}$ edição. Osford, USA: Oxford University Press: India, 2004.

Celebi, M.E.; Kingravi, H.A.; H. Iyatomi, Y.A.A.; Stoecker, W.V.; Moss, R.H.; Malters, J.M.; Grichnik, J.M.; Marghoob, A.A.; Rabinovitz., H.S. \& Menzies, S.W., Border detection in dermoscopy images using statistical region merging. Journal of International Society for Bioengineering, 14(3):347-353, 2008.

Chen, J.X. \& Liu, S., A medical image segmentation method based on watershed transform. In: International Conference on Computer and Information Technology. v. 1 de 1, p. 634-638. 2005.

Dermatlas, M.I., Dermatology image atlas. Disponível em http://dermatlas.med.jhmi.edu/derm, 2012. 
Dokur, Z. \& Ölmez, T., Segmentation of ultrasound images by using a hybrid neural network. Pattern Recognition Letter, 23:1825-1836, 2002.

Gonzalez, R.C.; Woods, R.E. \& Eddins, S.L., Digital Image Processing Using MATLAB. Upper Saddle River, NJ, USA: Prentice-Hall, Inc., 2003.

Goshtasby, A., Segmentation of skin cancer images. Disponível em http://www.cs.wright.edu/ agoshtas/paper_fig.html, 2012.

Guide, S.C., Skin cancer self-examination. Disponível em http://www.skincancerguide.ca/prevention/self_examination.html, 2012 .

Hashemi, S.; Kiani, S.; Noroozi, N. \& Moghaddam, M.E., An image contrast enhancement method based on genetic algorithm. Pattern Recognition Letter, 31:1816-1824, 2010.

Hudson, D.L. \& Cohen, M.E., Neural networks and artificial intelligence for biomedical engineering. IEEE, 2000.

Jianli, L. \& Baoqi, Z., The segmentation of skin cancer image based on genetic neural network. In: Proceedings of the 2009 WRI World Congress on Computer Science and Information Engineering. IEEE Computer Society, v. 5, p. 594-599. 2009.

Kass, M.; Witkin, A. \& Terzopoulos, D., Snakes: Active contour models. International Journal of Computer Vision, 1(4):321-331, 1988.

Lee, W.L.; Chen, Y.C.; Chen, Y.C. \& Hsieh, K.S., Unsupervised segmentation of ultrasonic liver images by multiresolution fractal feature vector. Information Science, 175:177-199, 2005.

Lu, R. \& Shen, Y., Automatic ultrasound image segmentation by active contour model based on texture. In: Proceedings of the First International Conference on Innovative Computing, Information and Control. IEEE Computer Society, v. 2, p. 689-692. 2006.

Ma, Z.; Tavares, J.M.R.; Jorge, R.N. \& Mascarenas, T., A review of algorithms for medical image segmentation and their applications to the female pelvic cavity. Computer Methods in Biomechanics and Biomedical Engineering, 13(2):235-246, 2010.

Morris-Smith, J.D., Characterisation of the appearance of pigmented skin lesions. Tese de doutorado, The University of Birmingham, 1996.

Mukhopadhyay, A. \& Maulik, U., A multiobjective approach to mr brain image segmentation. Applied Soft Computing, 11:872-880, 2011.

da Silva, I.N.; Spatti, D.H. \& Flauzino, R.A., Redes Neurais Artificiais: para engenharia e ciências aplicadas. $1^{\text {st }}$ edição. São Paulo, SP: Artliber, 2010.

Yoon, S.W.; Lee, C.; Kim, J.K. \& Lee, M., Wavelet-based multi-resolution deformation for medical endoscopic image segmentation. Journal of Medical Systems, 32:207-214, 2008. 


\section{Notas Biográficas}

Alex F. de Araujo graduou-se em Ciências da Computação na Universidade Federal de Goiás/Catalão em 2007. Obteve o grau de mestre em Ciências da Computação na Universidade Estadual Paulista "Júlio de Mesquita Filho"/São José do Rio Preto em 2010. Atualmente é doutorando em Engenharia Informática na Faculdade de Engenharia da Universidade do Porto.

João Manuel R. S. Tavares licenciou-se em Engenharia Mecânica na Faculdade de Engenharia da Universidade do Porto (FEUP) em 1992. Obteve os graus de Mestre e de Doutor em Engenharia Electrotécnica e de Computadores, também na FEUP, em 1995 e 2001, respectivamente. Desde 2001, é Investigador Sénior e Coordenador de Projeto no Laboratório de Óptica e Mecânica Experimental (LOME), do Instituto de Engenharia Mecânica e Gestão Industrial (INEGI) É Prof. Auxiliar do Departamento de Engenharia Mecânica (DEMec) da FEUP desde 2001 até 2011 e Prof. Associado do mesmo departamento desde 2011.

Roberta B. Oliveira graduou-se em Sistemas de Informação na Fundação Educacional de Fernandópolis em 2008. Atualmente cursa mestrado em Ciência da Computação na Universidade Estadual Paulista - São José do Rio Preto/SP.

Ricardo Baccaro Rossetti é médico, especialista em dermatologia, pesquisador do laboratório da clínica DERM, São José do Rio Preto-SP.

Norian Marranghello possui graduação em Engenharia Eletrônica pela Pontifícia Universidade Católica do Rio Grande do Sul (1982), mestrado em Engenharia Elétrica pela Universidade Estadual de Campinas (1987), doutorado em Engenharia Elétrica pela Universidade Estadual de Campinas (1992), pós-doutorado em Sistemas de Computação pela Universidade de Aarhus na Dinamarca (1998) e livre-docência em Sistemas Digitais pela Universidade Estadual Paulista (1998). Atualmente é Professor Titular da Universidade Estadual Paulista. Tem experiência nas áreas de Engenharia Elétrica e de Ciência da Computação, com ênfase em Sistemas Digitais, atuando principalmente nos seguintes temas: sistemas digitais integráveis, modelagem e simulação de sistemas, arquiteturas reconfiguráveis, redes de Petri e síntese de sistemas digitais.

Aledir Silveira Pereira é graduado em Engenharia Elétrica, sendo engenheiro Eletrônico e Eletrotécnico. Tendo obtido o título de mestre em Engenharia Elétrica pela USP - Universidade de São Paulo e título de doutor em Física Aplicada Computacional pela USP em 1995. Atualmente é professor assistente doutor pela UNESP - Universidade Estadual Paulista junto ao IBILCE Instituto de Biociências, Letras e Ciências Exatas - Campus de São José do Rio Preto. Tem experiência em processamento digital de imagens, sistemas digitais, automação controle industrial e ensino de computação. 